\title{
The application of nitrido manganese reagents to the synthesis of protected $\mathbf{N}$-methyl D-fucosamine
}

\author{
Erick M. Carreira, ${ }^{*}$ Jason Hong, Justin Du Bois, and Craig S. Tomooka
}

\author{
Division of Chemistry and Chemical Engineering 164-30 \\ California Institute of Technology \\ Pasadena, CA 91125, USA
}

\begin{abstract}
:
A synthesis of protected D-fucosamine and N-methyl fucosamine from D-galactose is described. The synthesis is carried out in ten steps and includes the amination reaction of Dfucal with an easily prepared $\mathrm{Mn} \equiv \mathrm{N}$ reagent.
\end{abstract}

\section{Introduction}

Heteroatom transfer to alkenes constitutes reaction methodology that is invaluable for the preparation of molecules of pharmacological and medicinal importance. Highly selective, efficient reagents and catalysts for alkene epoxidation and dihydroxylation have been described which are widely employed in synthesis $(1,2,3,4)$. In contrast, far fewer synthetically practical methods may be relied upon for the analogous single-step transfer of nitrogen to alkenes $(5,6,7)$. Such a direct alkene functionalization reaction should find significant applications in synthetic chemistry, allowing for more facile, expeditious syntheses of complex natural products (8) and pharmaceuticals.

We have recently reported that simple nitrido manganese complexes may be easily synthesized from common, readily available tetradentate and bidentate ligands $(6,7)$. These manganese reagents effect nitrogen transfer to alkenes, enol silanes, and glycals upon activation by trifluoroacetic anhydride. The process does not necessitate use of alkene reactants in excess and furnishes products with the nitrogen protected in the form of a trifluoroacetamide, a blocking group that is readily cleaved under mild conditions (9). The ability of glycals to function as substrates in the amination reaction considerably expands the scope of this transformation by providing access to 2-deoxy-2-amino sugars. In order to document the utility of theses reagents, we describe in this study an efficient synthesis of protected $\mathrm{D}$-fucosamine $\mathbf{1 a}$ and $N$-methyl $\mathrm{D}$-fucosamine $\mathbf{1 b}$. The preparation of these synthetically useful glycoside intermediates was conducted in ten steps utilizing inexpensive D-galactose as starting material.

\section{Background}<smiles>CC1OC(O)[C@H](NC(=O)C(F)(F)F)C2OC(C)(C)OC12</smiles><smiles>CO[C@H]1OC(C)[C@@H]2OC(C)(C)OC2[C@H]1N(C)C(=O)C(F)(F)F</smiles><smiles>[111InH2]</smiles>

2-Deoxy-2-amino sugars constitute a family of monosaccharides that are found in bioactive natural products (Fig. 1) of relevance to human medicine $(10,11)$. For example, $N$-methyl Lglucosamine is a component of the aminoglycoside antibiotic streptomycin 2 which is administered clinically against mycobacterial infections such as tuberculosis and leprosy (12). The $N$-acetamide deriative of D-2-galactosamine is a constituent of the human breast tumor antigen oligosaccharide $3(13)$, and $N$-sulfonated D-glucosamine is a critical monomer of the functionally active polyanionic oligosaccharide heparin 4 , the endogenous mammalian anticoagulant. Additionally, $N$-methyl fucosamine is the carbohydrate residue appended at the periphery of the reactive cumulene of the neocarzinostatin (NCS) chromophore 5, a prominent member of the enediyne family of antibiotics $(14,15)$. Extensive investigations of the mechanism of action of this remarkable antitumor agent have documented the critical role of $N$-methyl D-fucosamine in the chromophore in accelerating the rate and efficiency of DNA cleavage when compared to that of the aglycon (16). The N-methyl fucosamine is believed to accelerate the activation of NCS by serving as an internal base towards attacking thiols. However, the glycosylated cumulene chromophore once activated has been found to be more stable than the corresponding aglycon; it has been suggested that the carbohydrate residue confers steric protection by slowing bimolecular decomposition pathways. 


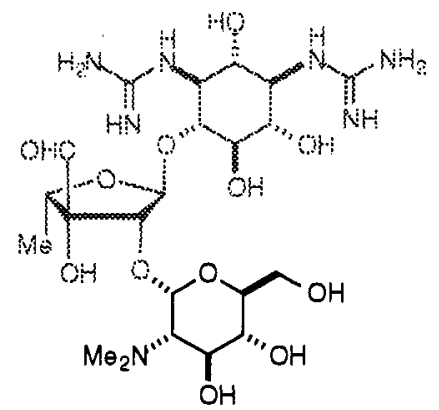

Streptomycin 2<smiles>CCCC(=O)O[C@H]1C=C2C#CC3([C@@H]4COC(=O)O4)O[C@H]3C#C/C=C\2[C@H]1O[C@@H]1O[C@H](C)[C@H](O)[C@H](O)[C@H]1NC</smiles>

Neocarzinostatin Chromophore 5

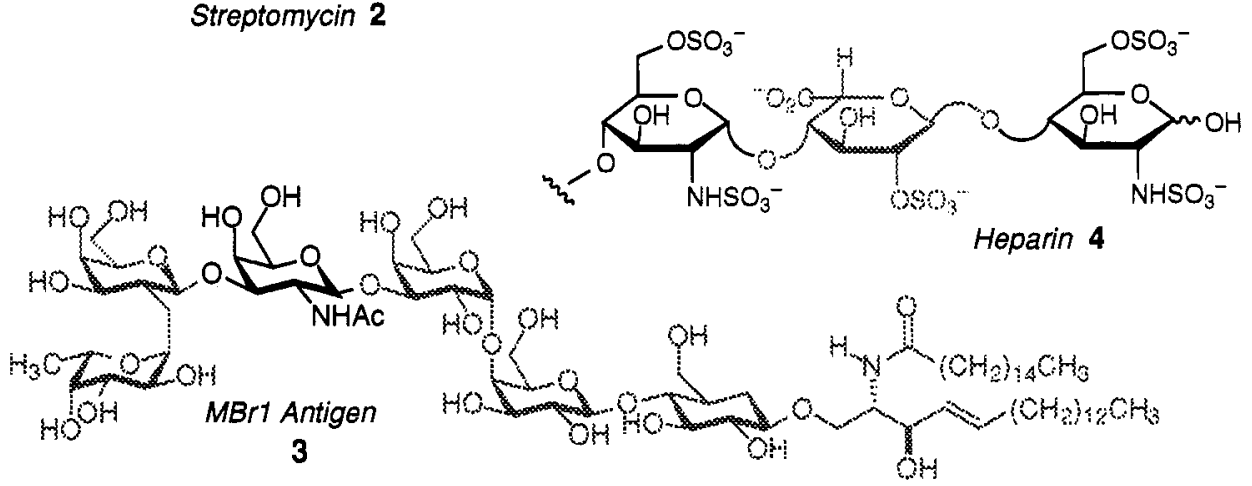

Fig. 1. Natural products incorporating 2-aminosugars.

Various synthetic approaches to 2-deoxy-2-amino sugars have been developed utilizing carbohydrate glycals as starting materials $(17,18,19,20,21,22,23)$. Two of these methods in particular have received considerable attention. In pioneering studies, Danishefsky has reported the reaction of glycals 6 with (sym-collidine) ${ }_{2} \mathrm{I}\left(\mathrm{ClO}_{4}\right)$ and $p$-toluenesulfonamide to afford 2 -iodo arene sulfonamide 7 (eq 1). In a subsequent step, the iodosulfonamide is treated with base to give a putative aziridine intermediate 8, which can be trapped by nucleophilic attack at the 1-position. Using this approach, Danishefsky has reported the landmark synthesis of a pentasaccharide that corresponds to the human breast tumor antigen 3 (13). In the second method, Fitzsimmons and Leblanc and co-workers have reported that glycals undergo hetero $4 \pi+2 \pi$ cycloadditions with dialkyl azodicarboxylates such as 9 to give 10 (eq 2) (23). The heterocyclic adducts can subsequently be reduced with $\mathrm{Ra} / \mathrm{Ni}$ to give the desired unprotected 2-amino sugars.

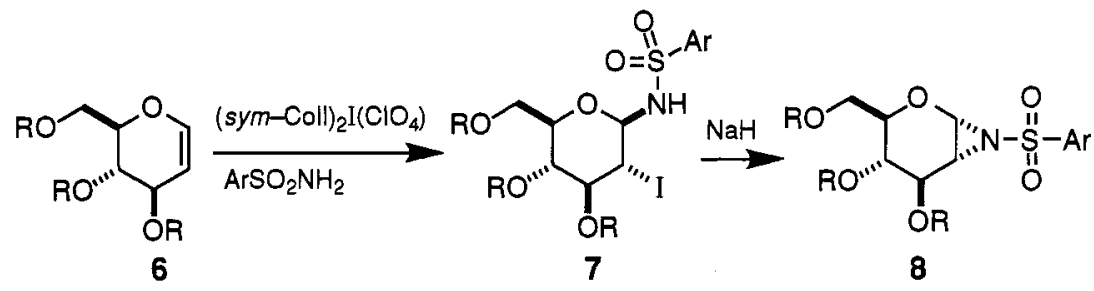

We have recently reported a process that utilizes a novel, easily prepared manganese nitrido complex which, upon activation with trifluoroacetic anhydride, serves as a reactive nitrogen transfer agent (Scheme 1) (6). This methodology offers several attractive and important features: (1) glycal 11 is used as the limiting reagent, (2) the amination reagent is oxygen- and moisture- stable and thus easily handled and amenable to storage, and (3) the products isolated (13) incorporate an amine conveniently protected as the $N$-trifluoroacetyl amide derivatives (9). 


\section{Scheme 1}

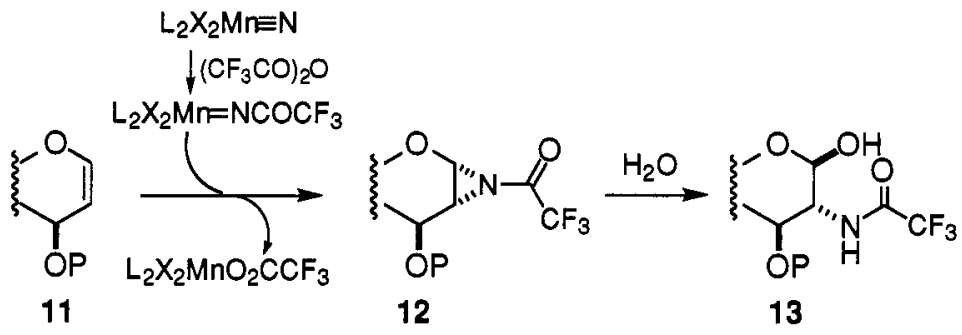

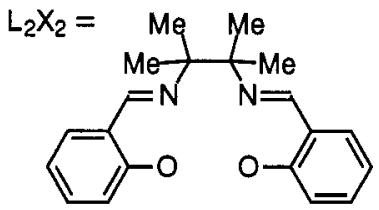

\section{Results and Discussion}

We have chosen $N$-fucosamine as a target for synthesis because it is a sugar that is not readily available from natural sources $(24,25)$. In addition, this target would provide an ideal setting to examine the application of the nitrido manganese reagents within the context of a functionally complex target molecule. Importantly, we required that the synthesis provide a fucosamine derivative possessing protecting groups that are tolerant of additional synthetic manipulations, such as glycosidation reactions and are, in turn, removed under mild conditions. Our interest in using nitrido manganese reagents dictates a glycal intermediate such as protected D-fucal 14 in the retrosynthetic analysis (Fig. 2). In principle, the ideal starting material for the synthesis of $N$-methyl D-fucosamine would be D-fucose 15 ; however, a route commencing with 15 suffers from the high cost of the starting sugar at \$27/gram (26). In contrast, D-galactose 16 possesses the desired stereochemistry at C-3, C-4 and C-5, and is available at only $\$ 0.08 / \mathrm{gram}$.

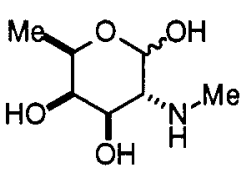

$\mathrm{N}$-methyl fucosamine

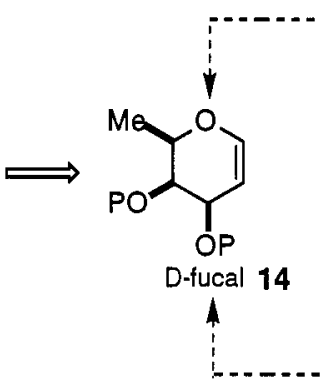<smiles>C[C@H]1O[C@H](O)[C@H](O)[C@H](O)[C@H]1O</smiles>

15

D-fucose<smiles>OCC1OC(O)C(O)C(O)C1O</smiles>

16

D-galactose

Fig. 2. Retrosynthetic analysis.

We have shown that salen-derived manganese nitrides can be prepared in large quantities (20-30 g). The complex is a diamagnetic, forest-green crystalline solid that can be easily handled and is amenable to prolonged storage. More recently, we have prepared additional simple nitrido
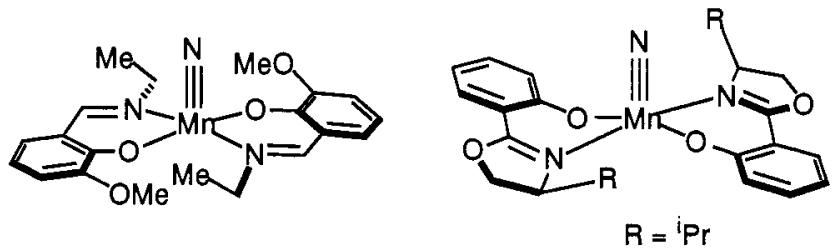

$$
\mathrm{R}=\mathrm{Ph}
$$

Fig. 3. Novel Mn nitrides prepared with bidentate ligands. 
manganese complexes derived from bidentate ligands that are also capable of serving as amination reagents towards unactivated alkenes (Fig. 3). The syntheses of nitrogen transfer reagents 21 and 22 used in this study were effected upon treatment of a methanol solution of the brown $\mathrm{Mn}^{\mathrm{III}}(\mathrm{OAc})$ complex 19 or 20 with $\mathrm{NH}_{4} \mathrm{OH}$ and Clorox bleach (Scheme 2). Under optimal conditions, (saltmen) $\mathrm{MnV}_{(\mathrm{N})} 22$ could be prepared in a single operation via reaction of the ligands 17 and 18 with $\mathrm{Mn}(\mathrm{OAc})_{2} \cdot 4 \mathrm{H}_{2} \mathrm{O}$ and subsequent in situ oxidation with Clorox bleach in the presence of $\mathrm{NH}_{4} \mathrm{OH}$. We have found that the saltmen derivative $\mathbf{2 2}$ is more widely soluble in commonly employed organic solvents and is therefore more convenient to use.

\section{Scheme 2}

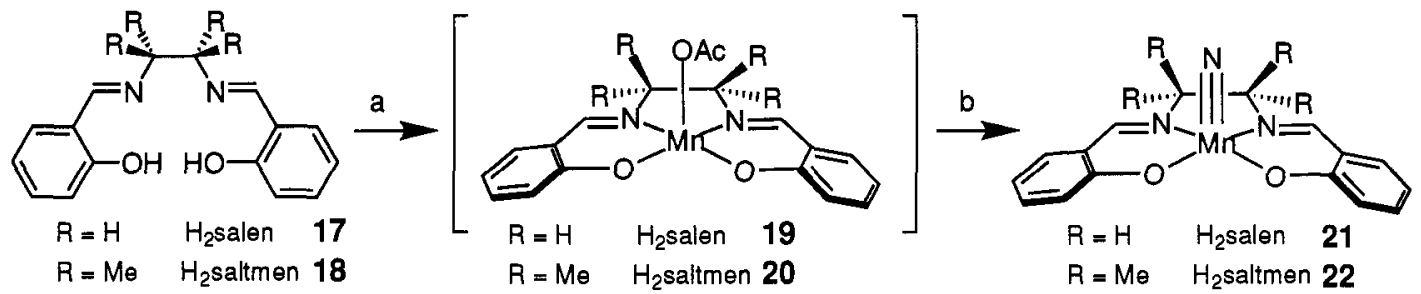

(a) $\mathrm{Mn}(\mathrm{II})(\mathrm{OAc}) 2 \cdot 4 \mathrm{H}_{2} \mathrm{O}, \mathrm{CH}_{3} \mathrm{OH}$, reflux; (b) $15 \mathrm{M} \mathrm{NH} 4 \mathrm{OH}$, Clorox, $23^{\circ} \mathrm{C}, 85 \%$

D-Galactose 16 was converted into tris- $O$-acetyl-D-galactal 23 in a single-step procedure involving peracetylation, selective hydrolysis of the anomeric acetate, conversion into the glycosyl bromide, and reductive elimination (69\%, Scheme 3) (27). Saponification of the acetate esters with alkaline methanol $\left(\mathrm{K}_{2} \mathrm{CO}_{3}, \mathrm{CH}_{3} \mathrm{OH}\right)$ afforded triol 24 in quantitative yield. Selective protection of the primary alcohol at $\mathrm{C}-6$ was effected in good yields upon treatment of 24 with tert $-\mathrm{BuPh}_{2} \mathrm{SiCl}$ (imidazole, DMF, $81 \%$ ). Ketalization of the cis-vicinal diol 25 (2,2-dimethoxypropane, PPTS, 85\%) provided 26. Following desilylative deprotection $\mathbf{2 7}$ was subsequently subjected to conditions to effect reductive deoxygenation at C-6.

Scheme 3

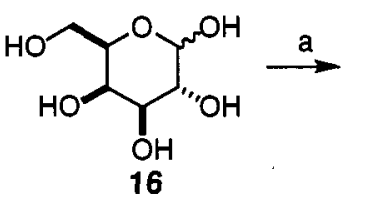<smiles></smiles><smiles>CC(C)C</smiles><smiles>CC1(C)O[C@H]2C=CO[C@H](CO)[C@H]2O1</smiles>
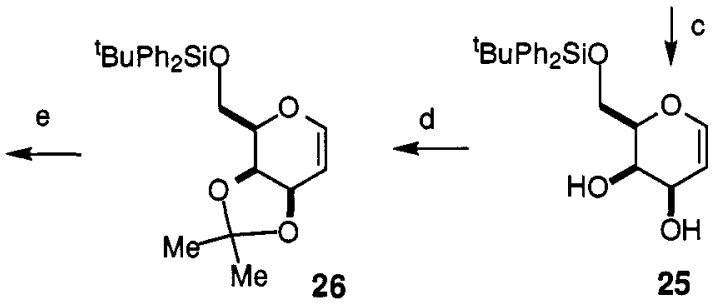

(a) (i) $\mathrm{Ac}_{2} \mathrm{O}, \mathrm{HClO}_{4}, 1 \mathrm{~h}, 40^{\circ} \mathrm{C}$ (ii) $\mathrm{P}, \mathrm{Br}_{2}, 3.5 \mathrm{~h}, 0$ to $23^{\circ} \mathrm{C}$ (iii) $\mathrm{Zn}, \mathrm{NaOAc} \cdot 3 \mathrm{H}_{2} \mathrm{O}$, $\mathrm{CuSO}_{4} \cdot 5 \mathrm{H}_{2} \mathrm{O}, \mathrm{AcOH}, \mathrm{H}_{2} \mathrm{O}, 12 \mathrm{~h}, \mathrm{O}^{\circ} \mathrm{C}, 69 \%$; (b) $\mathrm{K}_{2} \mathrm{CO}_{3}, \mathrm{CH}_{3} \mathrm{OH}, 5 \mathrm{~h}, 23^{\circ} \mathrm{C}$, quantitative; (c) TBDPS-Cl, imidazole, DMF, $6 \mathrm{~h}, 0$ to $23^{\circ} \mathrm{C}, 81 \%$; (d) 2,2-dimethoxypropane, PPTS, $23 \mathrm{~h}, 23^{\circ} \mathrm{C}, 85 \%$; (e) Bu4NF, THF, $4 \mathrm{~h}, 23^{\circ} \mathrm{C}$, $99 \%$.

A number of procedures were investigated for the conversion of the C-6 carbinol to the corresponding methyl moiety. For example, conversion of $\mathbf{2 7}$ to either the corresponding bromide $\left(\mathrm{PBr}_{3}\right)$ or iodide $\left(\mathrm{PBr}_{3}, \mathrm{NaI} /\right.$ acetone) followed by reductive dehalogenation with $\mathrm{Bu} 3 \mathrm{SnH} / \mathrm{AIBN}$ or LSelectride, respectively, did not provide the desired product. However, conversion of the free primary alcohol to the corresponding $O$-tosylate $\left(\mathrm{Ts}_{2} \mathrm{O}\right.$, pyridine, 100\%) and subsequent reduction of 28 with $\mathrm{LiAlH}_{4}$ (5 equiv) in refluxing THF afforded protected D-fucal 29 as a volatile oil in $69 \%$ yield (Scheme 4). Treatment of a solution $\left(-78^{\circ} \mathrm{C}\right)$ of glycal $29(0.1 \mathrm{M})$, (saltmen) $\mathrm{Mn}(\mathrm{N})(1.5$ equiv), and di-tert-butyl4-methyl-pyridine (1.5 equiv) in $\mathrm{CH}_{2} \mathrm{Cl}_{2}$ with trifluoroacetic anhydride (3.0 equiv) gave the $\mathrm{N}$ trifluoroacetylated protected 2 -fucosamine as a white solid in $69 \%$ yield. Analysis of 1a by ${ }^{1} \mathrm{H}$ NMR spectroscopy was consistent with it being formed as mixture of $\mathrm{C}-1$ epimers and a single trifluoroacetamide diastereomer at C-2. Treatment of 1a with $\mathrm{CH}_{3} \mathrm{I}(\mathrm{NaH}, \mathrm{DMF})$ effected concomitant formation of the methyl glycoside and $3^{\circ}$ amide $1 \mathrm{~b}$ which was isolated as a single anomer in $56 \%$ yield. 
Analysis of the ${ }^{1} \mathrm{H}$ NMR vicinal coupling constants to the $\mathrm{C}-2$ proton were consistent with the diequatorial isomer shown for $\mathbf{1 b}$.

\section{Scheme 4}<smiles>CC1(C)OC2C=COC(CO)C2O1</smiles><smiles>CC(C)(C)OCC1OC=CC2OC(C)(C)OC21</smiles><smiles>CC1OC=CC2OC(C)(C)OC12</smiles>

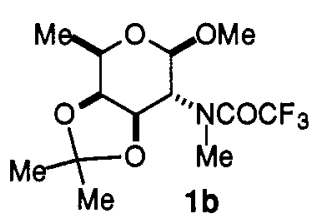

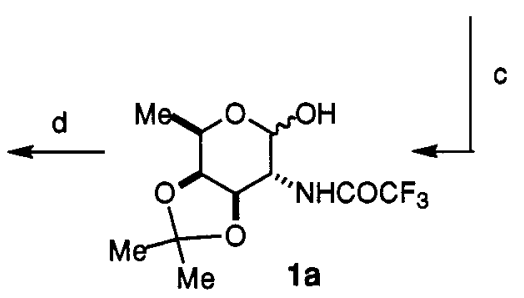

(a) $\mathrm{Ts}_{2} \mathrm{O}$, pyridine, $15 \mathrm{~h}, 23^{\circ} \mathrm{C}, 100 \%$; (b) $\mathrm{LiAlH}_{4}$, THF, reflux, $30 \mathrm{~h}, 69 \%$;

(c) (saltmen) $\mathrm{Mn}(\mathrm{N})$, TFAA, 2,6-di-t-butyl-4-methyl-pyridine, -78 to $23^{\circ} \mathrm{C}$,

$69 \%$. (d) $\mathrm{NaH}, \mathrm{DMF}, \mathrm{MeI}, 23^{\circ} \mathrm{C}$.

Previous studies have revealed a trend in which the preferential transfer of nitrogen to glycal substrates occurred from the olefin face opposite the allylic C-3 substituent. We had anticipated that nitrogen transfer to fucal 29 would be highly diastereoselective, since both C-3 and C-4 substituents are reinforcing the bias towards attack from the opposite alkene face. Additionally, protection of the diols in the form of an acetonide generates a bicyclic structure with an inaccessible concavity and an open convex alkene diastereoface (Fig. 4).
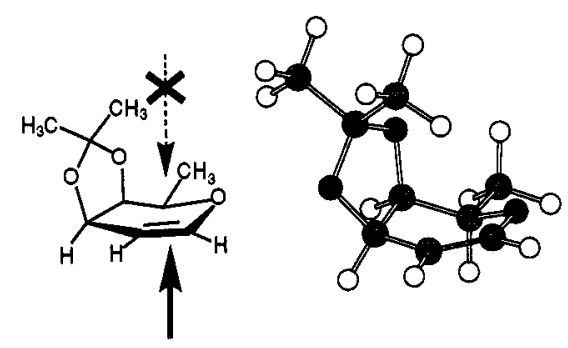

Fig. 4. Analysis of facial selectivity in amination reaction.

\section{Conclusion}

We have described an efficient synthesis of protected $N$-methyl $D$-fucosamine and $D$-fucosamine with protecting groups in each that are amenable to cleavage under mild conditions. The synthesis documents the use of readily prepared manganese nitrides as reagents for nitrogen transfer chemistry to substrates that are highly functionalized to provide rare amino 2-deoxy-2-amino saccharides. The salient characteristics of this method include: the use of the alkene substrate as the limiting reagent, an amination reagent that is oxygen- and moisture- stable and thus easily handled and amenable to storage, and the isolation $N$-trifluoroacetyl amide products.

\section{Acknowledgements}

$\mathrm{JH}$ thanks Pfizer for the gracious award of a Pfizer Undergraduate Summer Fellowship. JDB is grateful to the National Science Foundation (USA) for a predoctoral fellowship. This research has been supported by generous grants from the David and Lucille Packard Foundation, Sloan Foundation, NIH, NSF, Merck, Pfizer, Upjohn, Zeneca, and Lilly. 


\section{References}

1. (a) R. A. Johnson and K. B. Sharpless. In Catalytic Asymmetric Synthesis (I. Ojima, ed.), p 103. VCH, New York (1993). (b) E. N. Jacobsen. In Catalytic Aysmmetric Synthesis (I. Ojima, ed.), p 159. VCH, New York (1993). (c) K. A. Jørgensen. Chem. Rev. 89, 431 (1989). (d) B. E. Rossiter. In Asymmetric Synthesis (J. D. Morrison, ed.), p 193. Academic, New York (1985). (e) M. G. Finn and K. B. Sharpless. In Asymmetric Synthesis (J. D. Morrison, ed.), p 247. Academic, New York (1985).

2. (a) R. A. Sheldon and J. K. Kochi. Metal-Catalyzed Oxidation of Organic Compounds, Academic, New York (1981). (b) E. N. Jacobsen. In Comprehensive Organometallic Chemistry II (E. W. Abel, F. G. A. Stone, and G. Wilkinson, eds.), Vol. 12, 1097. Pergamon, Oxford, U. K. (1995). (c) S. I. Murahashi and T. Naota. In Comprehensive Organometallic Chemistry II (E. W. Abel, F. G. A. Stone, and G. Wilkinson, eds.), Vol. 12, 1177. Pergamon, Oxford, U.K. (1995).

3. (a) H. C. Kolb, M. S. VanNieuwenhze, and K. B. Sharpless. Chem. Rev. 94, 2483 (1994). (b) E. J. Corey and M. C. Noe. J. Am. Chem. Soc. 118, 11038 (1996), and references therein.

4. G. W. Parshall and S. D. Ittel. Homogeneous Catalysis, p 137. Wiley, New York (1992).

5. (a) G. G. Li, H. H. Angert, and K. B. Sharpless. Angew. Chem., Int. Ed. Engl. 35, 2813 (1997). (b) J. Rudolph, P. C. Sennhenn, C. P. Vlaar, and K. B. Sharpless. Angew. Chem., Int. Ed. Engl. 35, 2810 (1997), and references therein. (c) J. E. G. Kemp. In Comprehensive Organic Synthesis (S. V. Ley, ed.), Vol. 7, 469. Pergamon, Oxford, U.K. (1991). (d) D. A. Evans, M. M. Faul, and M. T. Bilodeau. J. Am. Chem. Soc. 116, 2742 (1994). (e) D. A. Evans, M. M. Faul, M. T. Bilodeau, B. A. Anderson, and D. M. Barnes. J. Am. Chem. Soc. 115, 5328 (1993), and references therein. (f) Z. Li, K. R. Conser, and E. N. Jacobsen. J. Am. Chem. Soc. 115, 5326 (1993).

6. (a) J. Du Bois, J. Hong, E. M. Carreira, and M. W. Day. J. Am. Chem. Soc. 118, 915 (1996). (b) J. Du Bois, C. S. Tomooka, J. Hong, and E. M. Carreira. J. Am. Chem. Soc. 119, 3179 (1997).

7. J. Du Bois, C. S. Tomooka, J. Hong, and E. M. Carreira. Angew. Chem., Int. Ed. Engl. in press (1997).

8. For a recent application of olefin amination within the context of a complex natural product synthesis, see: X. Tian, T. Hudlicky, and K. Königsberger. J. Am. Chem. Soc. 117, 3643 (1995).

9. The $N$-trifluoroacetyl protecting group may be cleaved under either mild hydrolytic or reductive conditions, see: T. W. Greene and P. G. M. Wuts. Protective Groups in Organic Synthesis, p. 353. Wiley, New York (1991).

10. (a) N. Sharon. Complex Carbohydrates, Their Chemistry, Biosynthesis and Functions. AddisonWesley, Reading, MA (1975). (b) J. F. Kennedy and C. A. White. Bioactive Carbohydrates. In Chemistry, Biochemistry, and Biology. Ellis Horwood, Chichester (1983).

11. (a) S. J. Danishefsky and M. T. Bilodeau. Angew. Chem., Int. Ed. Engl. 35, 1380 (1996). (b) H. J. M. Gijsen, L. Qiao, W. Fitz, and C.-H. Wong. Chem. Rev. 96, 443 (1996). (c) S. J. Danishefsky and J. Y. Roberge. Pure Appl. Chem. 67, 1647 (1995). (d) J. Banoub, P. Boullanger, and D. Lafont. Chem. Rev. 92, 1167 (1992). (e) R. R. Schmidt. Angew. Chem., Int. Ed. Engl. 25,212 (1986).

12. H. S. El Khadem. Carbohydrate Chemistry: Monosaccharides and their Oligomers, Chapter 7. Academic, San Diego, CA (1988).

13. For a leading reference, see: T. K. Park, I. J. Kim, S. H. Hu, M. T. Bilodeau, J. T. Randolph, O. Kwon, and S. J. Danishefsky. J. Am. Chem. Soc. 118, 11488 (1996).

14. Isolation of NCS: (a) J. Shoji. J. Antibiot. 14, 27 (1961). (b) N. Ishida, K. Miyazaki, K. Kumagai, and M. Rikimaru. J. Antibiot. 18, 68 (1965). (c) K. Edo, M. Mizugaki, Y. Koide, H. Seto, K. Hasuda, Y. Koyama, K. Edo, S. Katamine, F. Kitame, and N. Ishida. J. Antibiot. 33, 342 (1980).

15. Structure: (a) G. Albers-Schönberg, R. S. Dewey, O. D. Hensens, J. M. Liesch, M. A. Napier, and I. H. Goldberg. Biochem. and Biophys. Res. Commun. 95, 1351 (1980). (b) K. Edo, M. Mizugaki, Y. Koide, H. Seto, K. Furihata, N. Otake, and N. Ishida. Tetrahedron Lett. 26, 331 (1985). (c) K. Edo, Y. Akiyama, K. Saito, M. Mizugaki, Y. Koide, and N. Ishida. J. Antibiot. 39, 1615 (1986). (d) A. G. Myers, P. J. Proteau, and T. M. Handel. J. Am. Chem. Soc. 110, 7212, (1988). (e) A. G. Myers and P. J. Proteau. J. Am. Chem. Soc. 111, 1146 (1989). (f) K. -H. Kim, B.-M. Kwon, A. G. Myers, and D. C. Rees. Science 262, 1042 (1993).

16. A. G. Myers, M. E. Kort, and M. Hammond. J. Am. Chem. Soc. 119, 2965 (1997).

17. Nitrosylation: (a) W. J. Serfontein, J. H. Jordaan, and J. White. Tetrahedron Lett. 1069 (1964). (b) R. U. Lemieux and T. L. Nagabhushan, I. K. O'Neill. Tetrahedron Lett. 1909 (1964). (c) R. U. Lemieux and T. L. Nagabhushan. Tetrahedron Lett. 2143 (1965). (d) R. U. Lemiuex, S. W. Gunner, and T. L. Nagabhushan. Tetrahedron Lett. 2149 (1965). (e) R. U. Lemieux, T. L. Nagabhushan, and I. K. O'Neill. Can. J. Chem. 46, 413 (1968). (f) R. U. Lemiuex, T. L. Nagabhushan, K. J. Clemetson and L. C. N. Tucker. Can J. Chem. 46, 397 (1968). (g) R. U. Lemieux and T. L. Nagabhushan. Can J. Chem. 46, 401 (1968). (h) R. U. Lemieux and T. L. Nagabhushan. Methods Carbohydr. Chem. 6, 487 (1972). (i) K. Miyai and R. W. Jeanloz. Carbohydr. Res. 21, 45 (1972). (j) R. U. Lemieux, K. James, T. L. Nagabhushan, and K. Y. Ito. Can. J. Chem. 51, 33 (1973). (k) R. U. Lemieux, Y. Ito, K. James, and T. L. Nagabhushan. Can.J. Chem. 51, 7 (1973). (1) M. Kugelman, A. K. Mallams, and H. F. Vernay. J. Chem. Soc., Perkin Trans. 11113 (1976). (m) M. Kugelman, A. K. Mallams and H. 
F. Vernay. J. Chem. Soc., Perkin Trans. 11126 (1976). (n) A. K. Mallams, S. S. Saluja, D. F. Crowe, G. Detre, M. Tanabe, and D. M. Yasuda. J. Chem. Soc., Perkin Trans. 11135 (1976). (o) M. Kugelman, A. K. Mallams, H. F. Vernay, D. F. Crowe, G. Detre, M. Tanabe, and D. M. Yasuda. J. Chem. Soc., Perkin Trans. 11097 (1976). (p) H. Paulsen, P. Stadler, and F. Tödter. Chem. Ber. 110 , 1925 (1977). (q) K. Heyns and R. Hohlweg. Chem. Ber. 111, 3912 (1978). (r) G. Kavadias, R. Droghini, Y. Pépin, M. Ménard and P. Lapointe. Can. J. Chem. 57, 1056 (1979). (s) R. U. Lemiuex, F. F. Z. Georges, and Z. Smiatacz. Can.J. Chem. 59, 1433 (1981).

18. Haloazides: (a) J. S. Briacombe, J. G. H. Bryan, T. A. Hamor, and L. C. N. Tucker. J. Chem. Soc., Chem. Commun. 1401 (1968). (b) J. S. Briacombe, M. S. Saed, and T. J. R. Weakley. J. Chem. Soc., Perkin Trans. 1. 2061 (1980). (c) N. V. Bovin, S. E. Zurabyan, and A. Y. Khorlin. Carbohydr. Res. 98, 25 (1981). (d) D. Lafont and G. Descotes. Carbohydr. Res. 166, 195 (1987). (e) D. Lafont and G. Descotes. Carbohydr. Res. 175, 35 (1988).

19. N3\%CAN: (a) W. S. Trahanovsky and M. D. Robbins. J. Am. Chem. Soc. 93, 5256 (1971). (b) R. U. Lemieux and R. M. Ratcliffe. Can. J. Chem. 57, 1244 (1979). (c) J. Lehmann, W. Reutter, and D. Schöning. Chem. Ber. 112, 1470 (1979). (d) J. Arnarp and J. Lönngren. J. Chem. Soc., Perkin Trans. I 2070 (1981). (e) T. K. Shing and A. S. Perlin. Carbohydr. Res. 130, 65 (1984). (f) M. Forsgren and T. Norberg, Carbohydr. Res. 116, 39 (1983). (g) H. Paulsen, J. P. Lorentzen, and W. Kutschker. Carbohydr. Res. 136, 153 (1985). (h) H. Hashimoto, K. Araki, Y. Saito, M. Kawa, and J. Yoshimura. Bull. Chem. Soc.Jpn. 59, 3137 (1986). (i) H. Ammann and G. Dupuis. Can. J. Chem. 66, 1651 (1988). (j) H. Rembold and R. R. Schmidt. Carbohydr. Res. 246, 137 (1993). (k) W. Kinzy and A. Low. Carbohydr. Res. 245, 193 (1993).

20. Cr(II): (a) J. Lessard, H. Driguez, and J.-P. Vermes. Tetrahedron Lett. 4887 (1970). (b) H. Driguez, J.-P. Vermes, and J. Lessard. Can. J. Chem. 56, 119 (1978). (c) J. Lessard, M. Mondon, and D. Touchard. Can. J. Chem. 59, 431 (1981).

21. Os(VI): K. Heyns and J. Feldmann. Tetrahedron Lett. 2789 (1977).

22. (a) D. A. Griffith and S. J. Danishefsky. J. Am. Chem. Soc. 118, 9526 (1996). (b) D. A. Griffith and S. J. Danishefsky. J. Am. Chem. Soc. 113, 5863 (1991). (c) D. A. Griffith and S. J. Danishefsky. J. Am. Chem. Soc. 112, 5811 (1990).

23. (a) Y. Leblanc, B. J. Fitzsimmons, J. P. Springer, and J. Rokach. J. Am. Chem. Soc. 111, 2995 (1989), (b) Y. Leblanc and B. J. Fitzsimmons. Tetrahedron Lett. 30, 2889 (1989). (c) B. J. Fitzsimmons, Y. Leblanc, N. Chan, and J. Rokach. J. Am. Chem. Soc. 110, 5229 (1988).

24. For previous syntheses of $N$-methyl fucosamine, see: (a) V. Ojea, M. Ruiz, and J. M. Quintela. Synlett. 83 (1997). (b) D. Sames and R. Polt. J. Org. Chem. 59, 4596 (1994).

25. For related syntheses, see: (a) P. Szabó and D. Charon. Carbohydr. Res. 257, 145 (1994). (b) A. K. M. Anisuzzaman and D. Horton. Carbohydr. Res. 169, 258 (1987).

26. D-Fucose and D-galactose may be purchased from Aldrich Chem. Co., Inc.

27. This procedure has been employed with glucose: W. Roth and W. Pigman. In Methods in Carbohydrate Chemistry (R. L. Whistler and M. L. Wolfrom, Eds.), p 405. Academic, New York (1962). 